SOME YOINTS IN THE DESIGN OF BAI,I AND ROLLER BEARINGS. 107

\title{
SOME POINTS IN THE DESIGN OF BALL AND ROLLER BEARINGS.
}

\author{
By Prof. J. goodman.
}

\section{INTRODUCTORY .}

Although it has been known for some four or five thousand years that the resistance of a body to-sliding on a dry, flat plane is somewhere about thirty to forty times as great as when rollers are interposed between the surface and the plane, yet, strange to say, it is only within the last few years that rollers have been successfully applied to bearings. The reason why the attempts

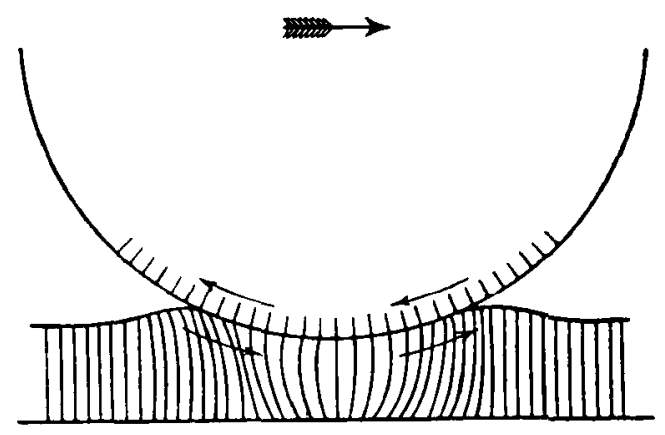

Fig. 1.

to do so have not been successful is one of the points the author hopes to deal with. He proposes to confine his remarks to the general principles underlying roller and ball bearings; others are much more competent to deal with the application of such bearings to automobile work.

The resistance to rolling of an elastic roller on an elastic path was first investigated by Professor Osborne Reynolds. 
The diagram, Fig. 1, illustrates the manner in which the surfaces are distorted, which gives rise to the resistance where rolling occurs. The resistance of an elastic roller on an elastic bed is entirely different from that of a cart wheel travelling: over a muddy road. Let the circumference of the roller be marked off in equal parts and the bed be similarly treated prior to the application of the roller, then when the latter is placed on the bed and caused to roll in the direction shown by the arrow, the bed will be depressed immediately under the roller and will be raised both fore and aft.

At the bottom of the hollow no slipping occurs between the roller and the bed, but on the hill sides there is distinct slipping between the roller and its bed. The relative direction of the

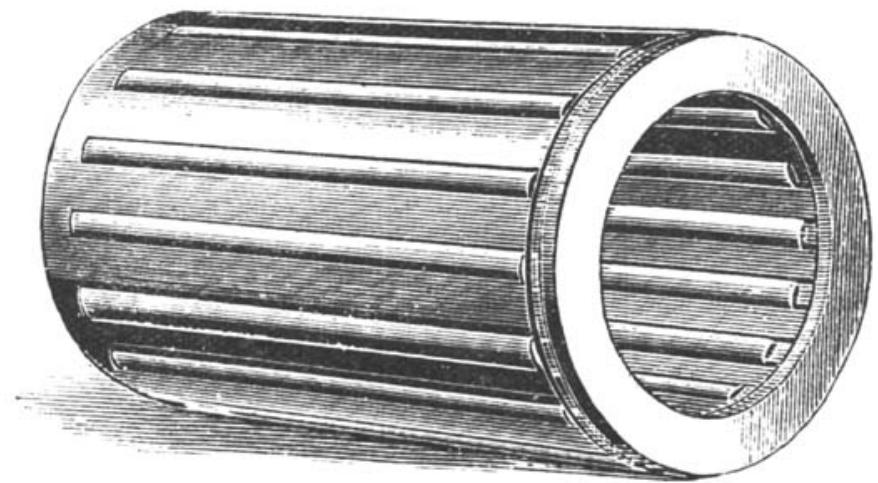

Fig. 2.

slipping, both fore and aft, is such as to impede the motion of the roller.

If a lubricant is interposed, such as oil or graphite, the width of the hollow strip over which no slipping occurs will be reduced, but the width of the slipping areas on both sides will be increased, which tends to increase the friction; but since the coefficient of friction is reduced by the lubricant, the one action almost counteracts the other, with the result that there is practically. no difference in the rolling resistanco when the surfaces are lubricated and when they are perfectly dry. In the case of a nearly perfect roller or ball bearing, exactly the same effect is experienced, namely, that the frictional resistance of a bearing is practically independent of lubrication. 
Owing to the stretching of the bed over which the roller travels, it is found that it does not roll through its geometrical distance; if a very accurate measurement of the distance that the roller moves is made and compared with the circumference of the roller, it will be found that the distance traversed always falls short of its geometrical distance. The amount of slip depends upon the nature of the surface, and the author's own tests show that, other things being equal, it depends also upon the load: Professor Osborne Reynolds, who first pointed it out, was unable to detect any slipping between a hard cast iron roller and a hard cast iron face plate over which the roller moved, which is not to be wondered at, since the amount of slip that occurs in such

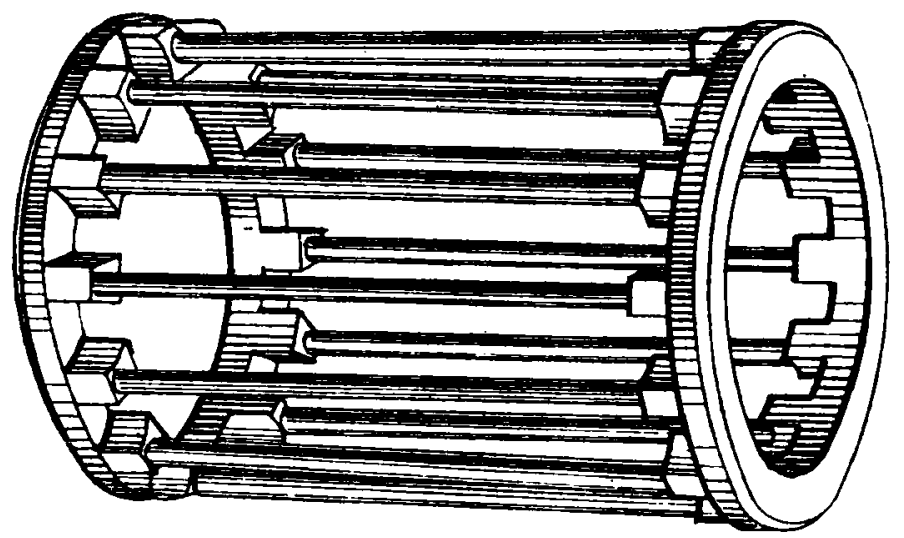

Fig. 3.

cases is very small, but in a roller or a ball bearing it is very easily measured, and it plays a very important part in certain instances, and it is important to remember that slipping always does take place whenever an elastic roller rolls on an elastic bed.

\section{ROLLER BEARINGS.}

In Fig. 2 is shown the cage and rollers of a representative of the old type of roller bearing. In this case, the shaft was fitted with a hardened steel sleeve accurately ground, and the casing was lined with a hardened steel liner. The rollers also were hardened and ground to size and were kept in position by a gunmetal cage. 
Another somewhat older type of eage is shown in Fig. 3. The rollers fit loosely in the slots, but unfortunately end thrust on the rollers is nearly always experienced in such bearings, causing the rollers to bear hard on the ends of the cage slots and to press the cage up against the flange of the casing, thus causing a very serious amount of friction, and giving rise to many other troubles which are not at all easy to overcome.

The very early roller bearing shown in Fig. 4 (Proceedings of the Institution of Civil Engineers, Volume XVIII.) was used on the axle of a railway train. The inventor evidently had trouble due to the rollers getting cross comered, and this he endeavoured
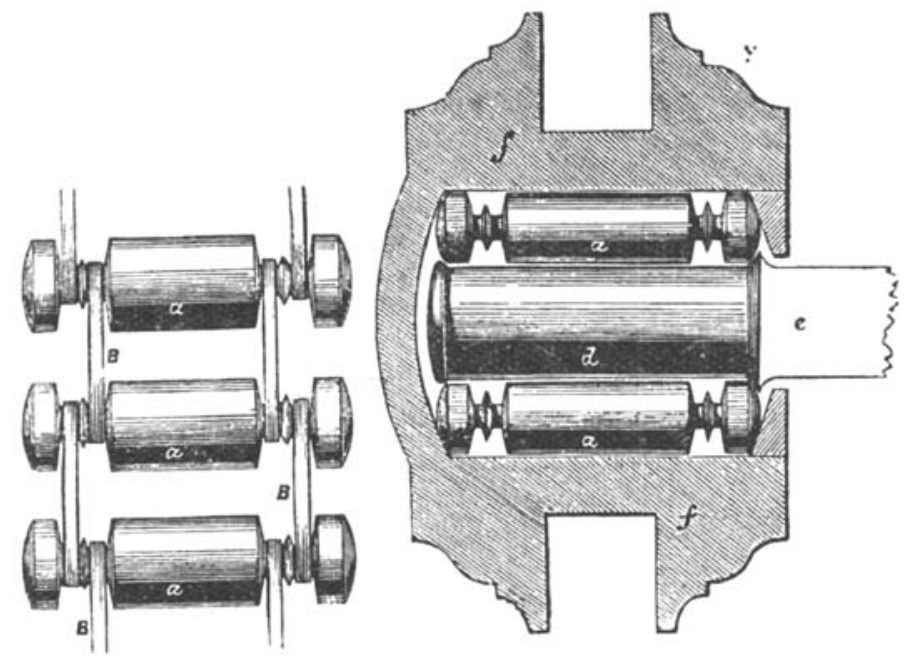

Fíg. 4.

to overcome by the very amateurish expedient of putting indiarubber bands on the ends of the rollers.

As regards the cause of end thrust, if the rollers are not absolutely parallel with the shaft, or if the rollers are the least bit tapered, or if the shaft or the sleeve on which it rolls is tapered, the rollers will tend to roll in a helical path on the shaft as it rotates. But the rollers cannot roll in a helical path, for the simple reason that the cage or the ends of the casing prevent them from doing so; hence the rollers crecp endwise until they press on the end of the cage and on the flange of the casing, and when the end pressure becomes sufficiently great, the rollers slip endwise 
and start afresh to roll in a helical path, and after a time slip back again. The author, by a very simple autographic arrangement on his testing machine, has recorded this action, and has shown that the rollers do behave in this manner. The amount of the end thrust depends very largely upon the load on the bearing, as far as can be detected it does not appear to vary at all with the amount that the rollers are out of truth.

End thrust is the source of very serious trouble. In some instances it causes the rollers to drill holes right through the end of the cage and through the casing. It also causes a very severe rumbling and vibratory action on the bearing, and it enormously increases the friction of the bearing. If a pure rolling motion

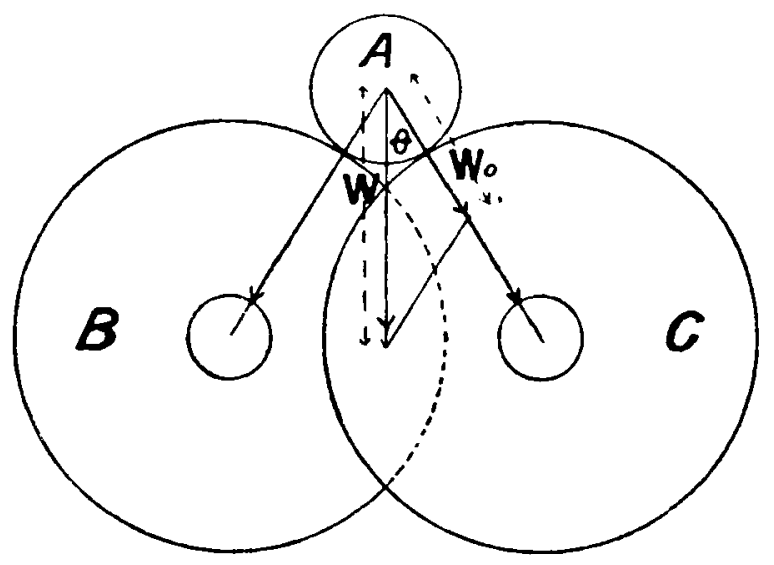

F'TG. 5.

of the rollers could be ensured without any end thrust the coefficient of friction would be in the neighbourhood of 1 in a thousand, whereas when end thrust is present it may easily be 1 in two or three hundred. The end thrust itself may, in aggravated cases, amount to, say, a quarter or a third of the total load on the bearing. Thus, with a 10-ton load on a bearing, the end pressure on the rollers and on the shaft tending to move them either to the right or to the left may amount to from $2 \frac{1}{2}$ to 3 tons. The direction of the end thrust always reverses when the direction of rotation of the shaft is reversed, but in certain cases its behaviour is very erratic. Sometimes the end thrust will be zero for a few minutes and suddenly get up to a maximum, and then 
reverse in direction. It is almost impossible in any given bearing to foresee in which direction the end thrust will occur, or even to estimate its amount.

Anti-friction rollers are shown diagrammatically in Fig. 5. They were used very largely in early days, and even at the present. day they are occasionally seen. The large disks $B$ and $C$ are mounted on axles, and the shaft $A$ rolls on the edges of the disks. Roughly speaking, the friction on the axle $\mathrm{A}$ is reduced in the ratio of the diameter of disk axle to the diameter of the disk, but it is quite impossible to use such a device for big loads, because the end thrust on the shaft becomes very serious. In the author's original friction testing machine, Fig. 23, he used such disks, but

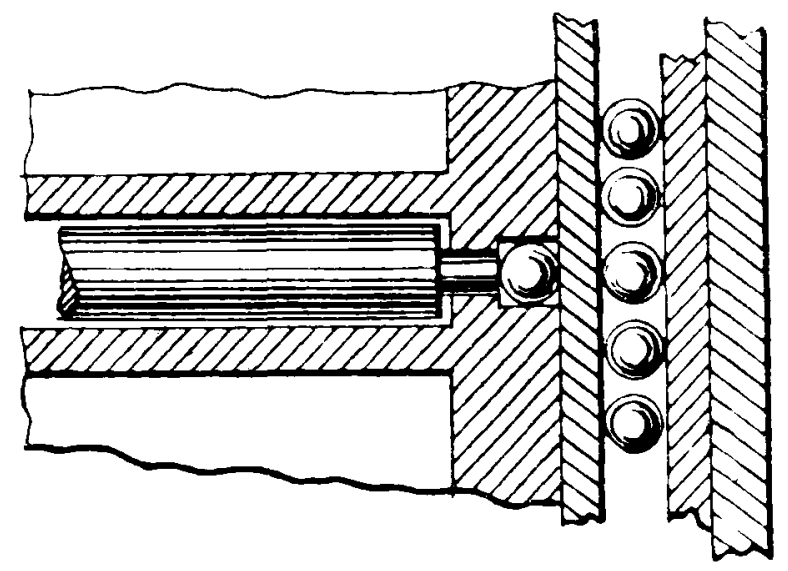

Fİส. 6.

he was obliged to put a ball thrust bearing on the axle $\mathrm{A}$ in order to prevent it from travelling endwise. A somewhat similar bearing has been recently applied to railway vehicles, but instead of two disks a single disk is used with the shaft A immediately below the disk axle and guides on both sides of the shaft $A$ keep it in position; one railway company has some thousands of wagons fitted with this appliance, some of which appear to run successfully, but many of them have given a great deal of trouble.

Amongst the early tests that were made by the author in order to overcome end thrust, the ends of the rollers were turned down, as shown in Fig. 6, and a ball was placed at the end of each roller to take the thrust. A ball was used because it was more convenient 
than a conical lathe centre. The author has been criticised for using a ball in this manner, but as a matter of fact, a ball loaded thus will work satisfactorily under quite big loads; he knows instances of vertical shafts carrying loads of over 2 tons running on nothing but a one inch ball resting on a plain piece of hardened steel. For the small amount of end pressure on these rollers the ball answered admirably. In order to reduce the friction between the cage and the casing, two hardened steel thrust rings and balls were fitted. The arrangement was made mainly for experimental purposes. A series of tests were carried out on the bearing with and without the balls, the friction and the end thrust being carefully measured. When the balls were interposed, the friction on the bearing was reduced by about 35 per cent, thus showing that a very large amount of the total friction in the original bearing was due
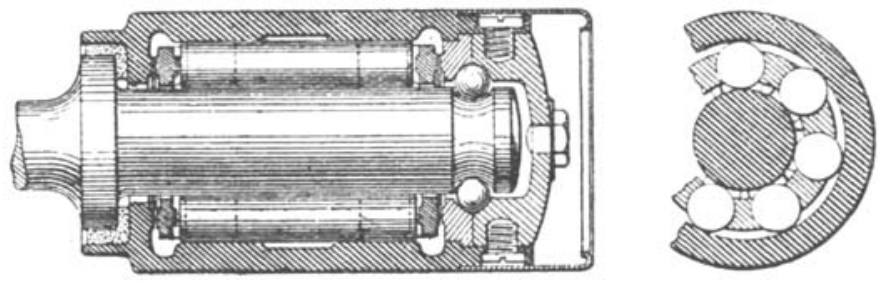

FIG. 7 .

to the friction between the end of the cage and the flange of the casing. Such an arrangement could be used in practice, but it would not be wise to do it, since ball bearings and other types of roller bearings can now be purchased which are very much cheaper and better. It was simply done for an experiment, and answered the purpose so far as it went, in showing that the end thrust was the source of a great deal of friction.

A somewhat similar arrangement was actually used in the Empire roller bearing (see Fig. 7), where a ball bearing was put in to take the end thrust. It answered fairly well, but it is not used at the prosent day. It adds somewhat to the expense, and is not altogether satisfactory, but the fact that makers of roller bearings have been obliged to resort to some such expedient to take up the end thrust on the rollers shows the reality of the: trouble. 
A cheap form of roller bearing, such as is used on small trucks for light railway purposes, is shown in Fig. 8. The rollers are nothing but short pieces of mild steel with rounded ends, and no cage is used. It is the very cheapest form of roller bearing it is possible to get, and it gives just as good results as some of the most expensive ones.

Very shortly after starting on these roller bearing tests, the author suspected that much of the trouble with regard to end thrust was due to imperfect workmanship. Two bearings were therefore ordered from a firm who had a reputation for turning out the very best quality of roller bearings. It was specified that they were to be made as perfect as possible as regards accuracy of workmanship, i.e., within one ten-thousandth of an inch in all the important points. When received they were
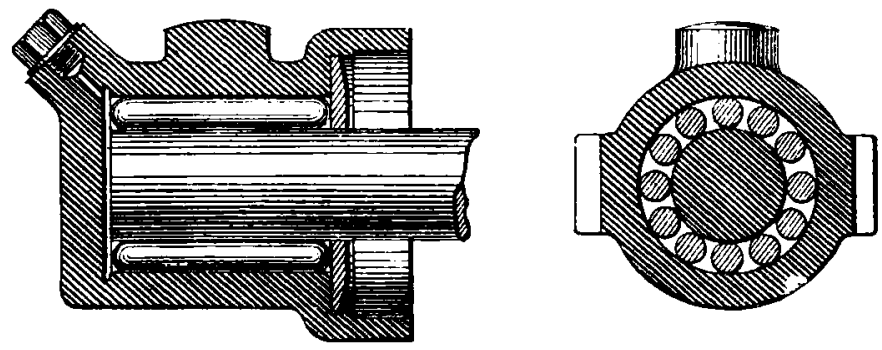

FIG. 8.

found to be well within the specification. They cost their weight in silver, but it was necessary to get great accuracy in order to find out whether the troubles due to end thrust could be avoided by accurato workmanship, because if accurate workmanship would get over the trouble it was regarded as being a very simple matter to design automatic machinery to ensure the necessary degree of accuracy commercially. Unfortunately, however, these bearing's, which cost so much, gave no better results than the very cheapest bearing on the market, which conclusively proved that end thrust troubles could not be overcome by simply securing accurate workmanship, and it showed, moreover, that the ordinary form of roller bearing was hopeless.

It was thought that possibly the long rollers bent to a certain extent under the load, and the next attempt was to use short rollers 
(Fig. 9). The results were decidedly better, the end thrust was less and the friction lower with the short rollers than with the longer rollers, but it was by no means an unqualified success.

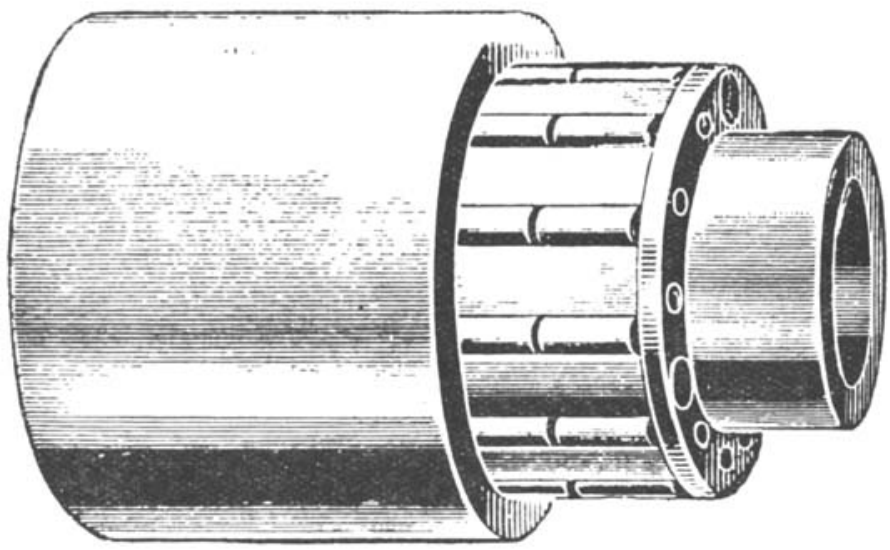

FIa. 9.

Another type of roller bearing that has been used to a very large extent is the Hyatt roller bearing (Fig. 10). In this case

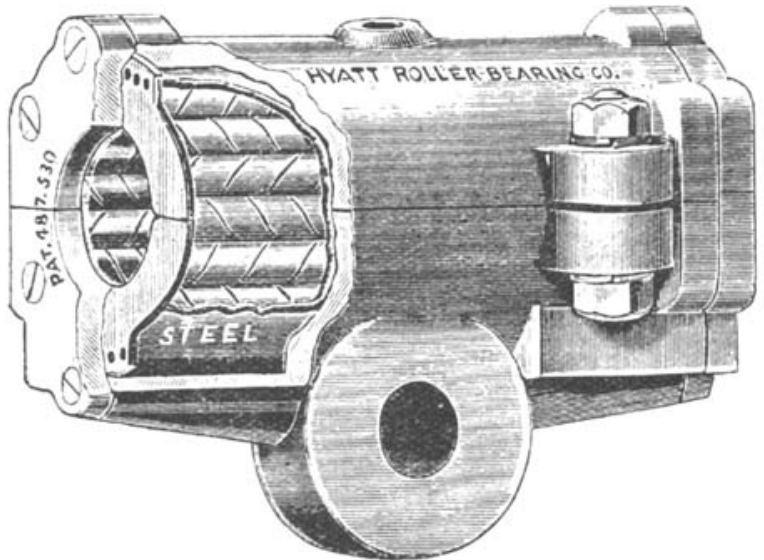

FIg. 10.

the rollers are made of helical springs, in some cases hardened and ground and in some cases not. The helical rollers are made н 2 
one with a left-handed helix and the other with a right-handed helix, with the hope that the one roller will tend to travel to the left and the other to the right, and so overcome the resultant end thrust on the bearing. To a large extent this is so, and for light loads per square inch of bearing area these bearings have been a success, for instance, in shafting, ete., but the loads they will carry are very small for a given length of bearing surface as compared with a high class roller or ball bearing.

The American roller bearing shown in Fig. 11, Plate I., was

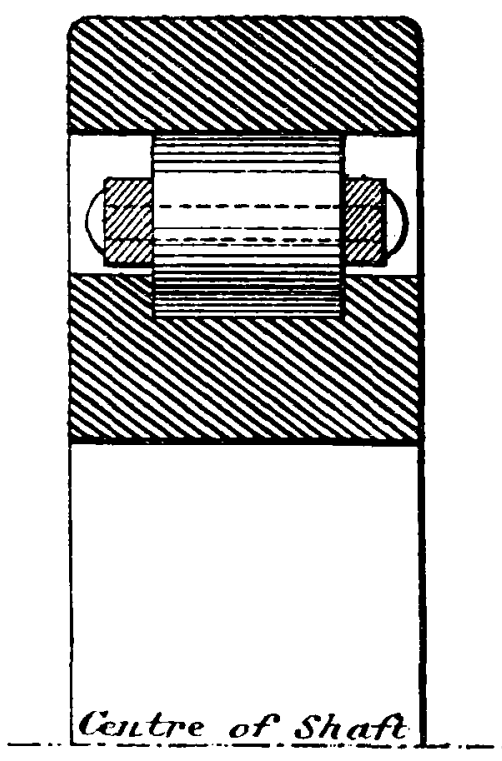

Fig. 12.

purchased from a firm which guaranteed that there was no end thrust whatever upon it, but when it was put in the testing machine the end thrust was so great that it smashed the end thrust gear of the testing machine.

In the roller bearing shown in Fig. 12, which has recently been put on the market, the length of the roller is equal to the diameter. It runs in a hardened steel and beautifully ground grooved sleeve, and a hardened steel liner in the bearing; the rollers themselves are hardened and ground with the same degrec of accuracy as the balls and races in a ball bearing. This is 
the only roller bearing the author has come across that is satisfactory under big loads. The end thrust is very small. One of the bearings that was tested showed a little end thrust at first, but after it had been running a few weeks it disappeared entirely. It was kept running for over a year; it ultimately failed, but only when subjected to a much higher load than a ball bearing of the same external dimensions. If the movement of the rollers with regard to the sleeve be examined, it will be seen why there is little or no end thrust upon it. When the rollers get askew, the flange of the sleeve tends to correct it; this is the only case known of by the author in which a roller bearing is practically free from end thrust.

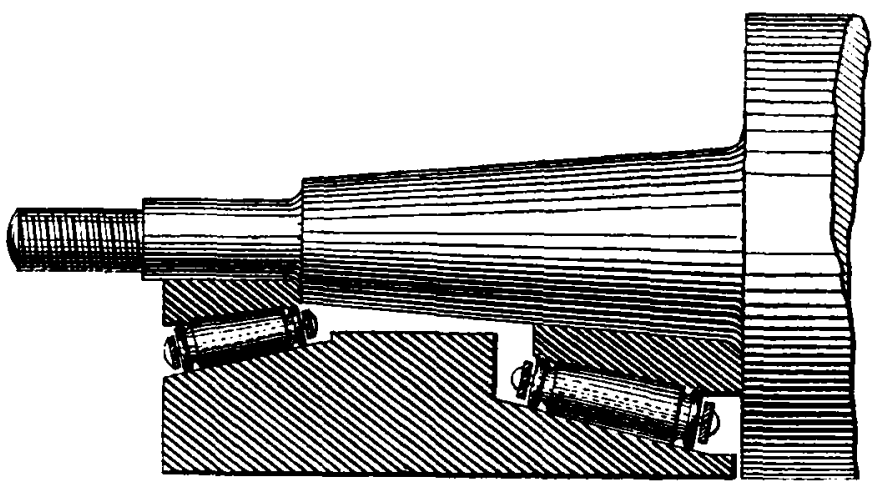

FIG. 13.

The bearing shown in Fig. 13 is one that has, perhaps, more interest for those who are connected with the automobile trade. The author carried out some tests on a bearing of this type some years ago, and up to the very moderate loads under which it worked it certainly ran well. In actual practice on automobiles it is said to be quite satisfactory.

A thrust roller bearing with conical rollers is shown in Fig. 14. The rollers, in the author's opinion, are far too small. It will shortly be shown that the safe load at which a bearing will run depends not so much upon the rotatory speed of the shaft as upon the rotatory speed of the rollers. One of these bearings, which was intended to take the thrust of a propeller shaft on a yacht, 
was submitted for testing prior to use in order to see that it was all right; the instructions were that it was to be run under a certain load at a certain speed, which were considered to be far too high. Hence a preliminary run was made at about one-half the load at which it was intended to work. It was very interesting from a pyrotechnical point of view. In a few minutes it looked more like a Catherine wheel than a roller bearing, but since it was not intended for that purpose it was never put into the yacht. Other bearings of this type, with larger rollers, have been used, but with a larger roller the taper becomes so great that the outward thrust of the rollers tends to burst the cage.

To sum up the end thrust troubles, the friction on the bearing is enormously increased by the end thrust; the wear may be
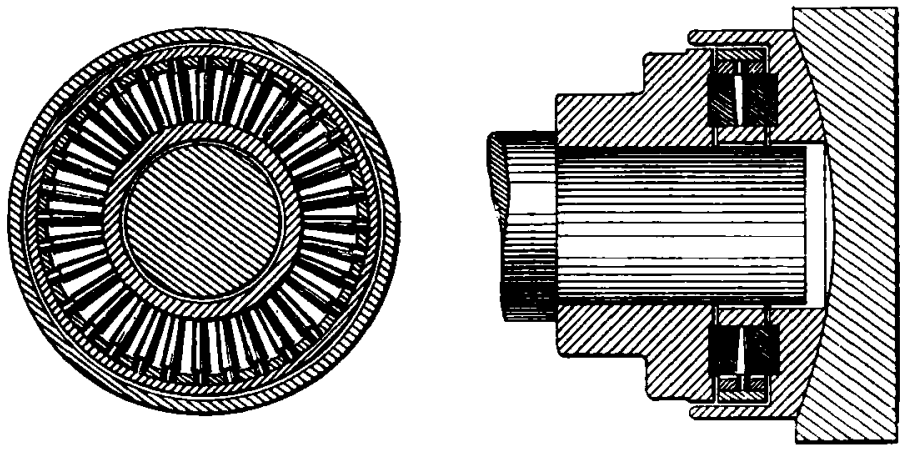

Frg. 14.

very serious, and there is a large amount of rumbling and vibration. Some years ago some roller bearings were used for shafting in a factory in Leeds, but on the floor above there was a chemical laboratory from which serious complaints were constantly received to the effect that the vibration arising from the bearings below was so severe that the bottles were shaken off the shelves. The roller bearings were taken out and ordinary bearings substituted for them.

With a properly designed roller bearing in which there is no end thrust, the friction is, to all intents and purposes, independent of lubrication, but when there is a large amount of end thrust lubrication makes a very great difference, for the simple reason that when there is no end thrust a pure rolling motion is secured, 
but when there is end thrust there is a large amount of friction between the end of the cage and the flange of the casing.

The friction is almost independent of the speed in a good roller bearing, but it decreases somewhat with the speed when there is end thrust. In all roller bearings the starting effort is very little greater than the running effort, which is a very great point in their favour, especially for certain types of machinery where there is constant stopping and starting. Even with the worst roller

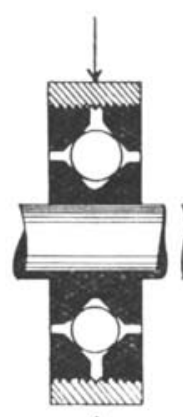

A

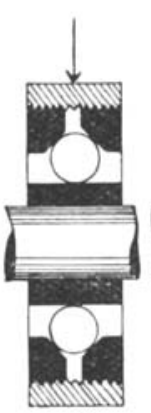

B

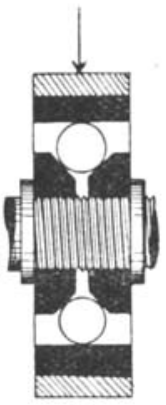

C

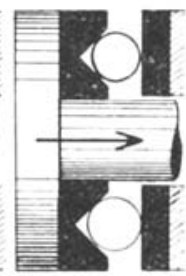

$\mathrm{H}$

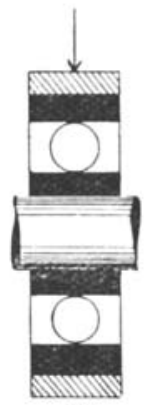

D

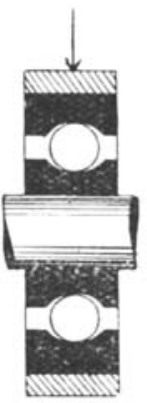

$E$

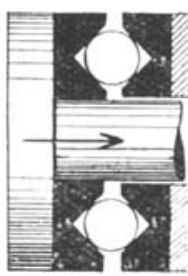

$\mathrm{F}$

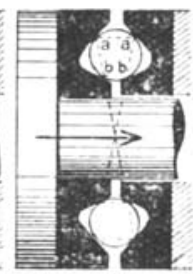

G

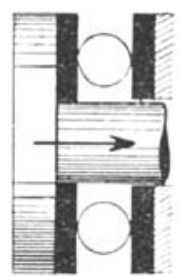

1

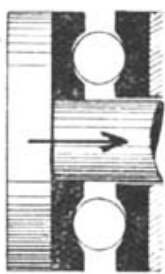

$\checkmark$

Fra. 15.

bearings the friction is lower than with ordinary bearings which are only provided with poor lubrication. With the best roller bearings the friction is lower even than with an ordinary bearing running in a bath of oil.

\section{BALL BEARINGS.}

In the modern ball bearing there is no end thrust, and the friction is very much less than in the majority of roller bearings, hence there is a great deal to be said. in favour of ball bearings. 
On the other hand, it is often urged that since a ball only bears upon a point, whereas a roller bears upon a line, therefore the carrying capacity of a ball bearing of a given size cannot possibly be so great as that of a roller bearing. There is an element of truth in the contention, but it is not the whole truth. With equally good material and workmanship in rollers and balls, and provided that there is no end thrust on the roller bearing, the argument would hold rigidly, but since end thrust with its attendant troubles does exist, in practice a ball bearing of given dimensions, with one exception, is able to carry a much bigger load than any roller bearing of the same external dimensions.

Different types of ball bearings are shown in diagrammatic form in Fig. 15. The earliest type of ball bearing, A, was formed with a steel sleeve having either a $\mathrm{V}$ or a rounded groove in the sleeve, and the outer races consisted of two conical rings which screwed into a casing tapped with a fine thread, with the idea that the bearing could be adjusted as it wore. Nearly all the early workers aimed at making ball bearings adjustable, but it was a great blunder, because the stationary cones only wear on the loaded side, hence when the conical ring is screwed up the balls run partly on the worn and partly on the new portion. Hence the new path on which the balls have to run is not even circular, consequently it is impossible to get anything like accurate adjustment with a bearing of that type.

The next type of bearing was made with a flat sleeve and cones, B. Later on, the sleeve consisted of two conical rings both screwed on to the shaft, and the outer stationary portion was made either plain or grooved, $\mathrm{C}$. With such an arrangement, a much better adjustment could be obtained, because the adjustable ring was always rotating, and therefore wore fairly evenly all over. Although the adjustment was not perfect, and the arrangement was not altogether satisfactory, it was a great deal better than that first mentioned. As has been said, it is a great piece of folly to attempt to take up wear or to adjust ball bearings.

Later on, two point plain cylindrical ball races, $D$, were used with a cage to keep the balls in position. The author believes that he was the original inventor of the two point ball bearing. Last of all the two point ball bearing was made with grooved races, E. At first, the races were made with the radius of the groove equal to the diameter of the ball, or twice the radius of the ball. In modern practice a very much smaller groove radius is used, somewhere in 
the neighbourhood of $9 / \mathbf{1 6}$ the radius of the ball. The reason for keeping the radius small will be seen later on. The earliest end thrust bearings, F, were made with 45 degree grooves. They, however, were found to be anything but satisfactory. The balls grated, and got very much scratched during running. In one of the author's early tests on a bearing of this type, the balls, which were about $1 \frac{1}{4}$ in. diameter, looked like badly-used golf balls after the test.

The next attempted improvement was to make the races unsymmetrical, G. In these unsymmetrical races, the races were intended to be so formed as to give the ball a true rolling motion similar to that of a conical roller in a roller bearing. It was a great deal better than the former, but still quite unsatisfactory: in running. In some of the tests the author made on bearings of this type, the grooves were ground with the greatest possible legree of accuracy, and the greatest possible care was taken in the manufacture. It was always found, however, that the bearings heated up at first, but after running a day or two they settled down and the friction got to a minimum. Then, curiously enough, if the load were increased or decreased the friction invariably went up and heating occurred again. This was probably due to the fact that when the load was altered the shape of the races altered, and after it had been running for two or three days the balls got properly bedded, but when the load was altered the shape of the races was again slightly altered, and the balls were no longer properly bedded. It was anything but a satisfactory bearing, although the friction was certainly lower than in the first mentioned bearing, and the balls lasted rather longer.

In the next type of bearing, $\mathrm{H}$, a single $\mathrm{V}$ groove was used for one race and a flat surface for the other. This was an improvement, but still not satisfactory.

The next type of bearing, I, was made with flat rings and a cage to hold the balls. It ran perfectly, and gave not the slightest trouble, and the balls improved with use, while the friction was in the neighbourhood of one-third of that with the Vee grooved races. An improvement on the flat race from a load carrying point of view was the grooved race, $J$. The friction, however, on grooved races is always slightly higher than the friction with the flat races, but the great advantage with the grooved races is that they will carry from 2 to $2 \frac{1}{2}$ times as much load as a flat race, but for certain purposes the 
flat raced bearing is better than the grooved type. If there is any chance of the shaft getting out of line with its housing, the flat raced bearing is the safer, although the working load for it is lower than for the grooved race.

\section{Importance of Accuracy in Manufacture.}

In the early days of ball bearings, say, twenty-five or thirty years ago, bearings gave a great deal of trouble, the reason being: very largely due to the fact that the balls and the races were not

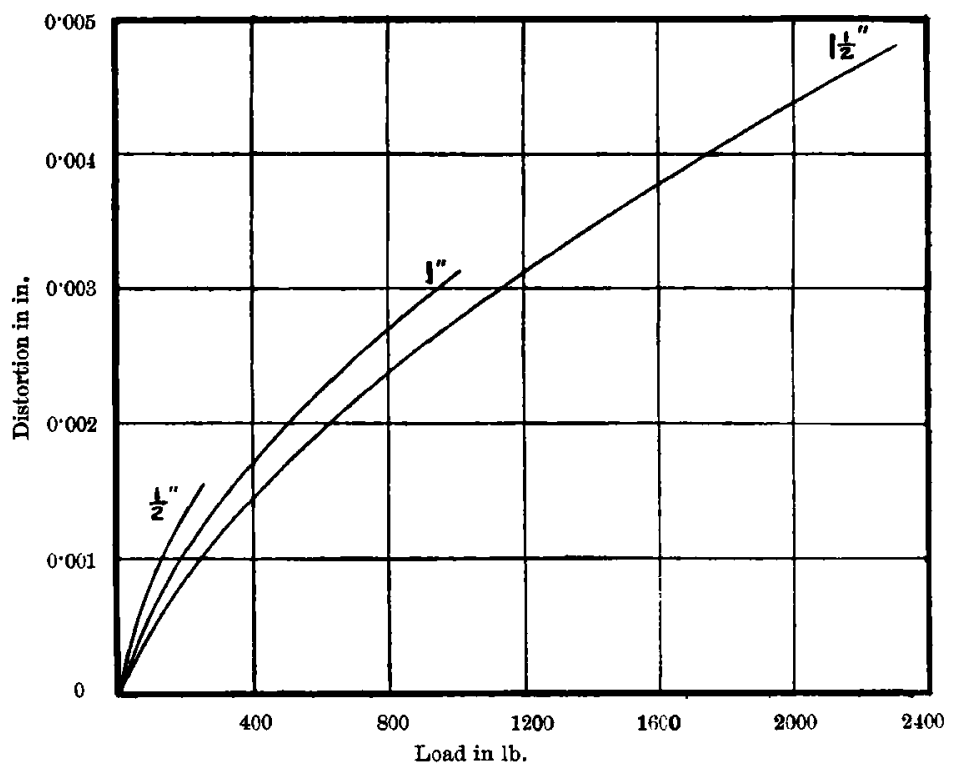

Fig. 16.

made with a sufficient degree of accuracy. If there is one thing above all others that experience has taught us it is the importance of accuracy in manufacture and perfection of finish. The ball bearing of to-day could never have been made a commercial success but for automatic machinery for turning out the balls and the races to a very high degree of accuracy. The importance of getting accurate workmanship can be judged from Fig. 16, which shows the amount of distortion of balls when loaded. For example, with a half-inch diameter ball, the curves show that a distortion to the extent of one thousandth of an inch corresponds 
to a load of about $130 \mathrm{lb}$. on the ball. Hence if one of the balls in a thrust bearing is a thousandth of an inch larger than the rest, that ball will have about $130 \mathrm{lb}$. more load upon it than the remainder of the balls. The total load that may be put on a half-inch ball when running at a very low speed is somewhere in the neighbourhood of $250 \mathrm{lb}$. Hence an error of one thousandth of an inch in the dimensions of the ball, or a high place to the extent of one thousandth of an inch in the race, will increase the load to such an extent that failure of the ball is certain to occur. With a one inch ball the safe load is somewhere in the neighbourhood of $1,000 \mathrm{lb}$., and the effect of a thousandth of an inch error is $200 \mathrm{lb}$. At high speeds the safe loads per ball are very much lower than at low speeds; hence, with a fast-running bearing it is of vastly more importance to get extreme accuracy in workmanship than it is with a slow-running bearing, and a defect to the extent of one thousandth of an inch in the dimensions of the ball or in the races is absolutely fatal to a ball bearing. In the bearing shown at $\mathrm{A}$ in Fig. 15, in which adjustment was obtained by screwing up one of the cones, it will be seen that if the bearing has worn on one side to the extent of a thousandth of an inch, any attempt to adjust it will simply ruin it.

In ball bearings there is always a small amount of slipping: between the balls and the sleeve. It is a perfectly simple matter to prove that the speed of rotation of the cage in a thrust bearing is one-half of the speed of the shaft. In order to measure the slip, very light counters can be attached, one to the shaft and one to the cage. The bearing is then allowed to run under various loads for considerable periods, and the difference between the counters shows the amount of slip of the balls on the races, which it is found depends very largely upon the load. A good many makers in the early days - they probably would not dare to make the statement now-used to say: "Well, what does it matter if the balls are not all exactly the same size to start with? Suppose some of the balls are a few ten-thousandths of an inch bigger than their neighbours. After the bearing has been running for a short time the larger balls will wear more than the smaller ones, and after a few weeks' or even a few days' running they will all be of approximately the same size, and will all work smoothly." That, however, is entirely fallacious, for this reason. The balls themselves run in a cage, which determines their distance apart. But since the large balls get a larger proportion of the load than 
the small ones, the amount of slip on the large balls will differ from that on the small ones, hence the speed at which they tend to run will differ. But the speed cannot differ, because they all travel in the same cage; therefore, either the large or the small balls must slip, and it stands to reason that the balls which slip are those which are subjected to the smallest load. Consequently, the small balls spasmodically slip, with the result that they get scratched and damaged, whereas the large balls remain perfect, which is exactly the reverse of what used to be contended by roughand-ready makers of ball bearings. It is, therefore, of vital importance to get all the balls of the same exact size as nearly; as possible. All the best makers to-day produce balls guaranteed to be within one ten-thousandth of an inch of their nominal size. Second grade balls can be purchased in batches, which as regards material and workmanship are as good as the first grade, but they are, perhaps, from one to three ten-thousandths of an inch below their nominal size; such a departure, of course, does not matter if all the balls in one bearing are of the same size, but it is impracticable to mix second grade balls from one consignment with those from another consignment, because there may be a difference of two or three ten-thousandths of an inch between them which is certain to result in failure. Some slipshod firms are careless in this respect, which to a very large extent accounts for many of the troubles experienced with their cheap and nasty. bearings.

\section{Wear of Balls.}

The wear of a properly made ball bearing is practically nil. In the author's early tests, which were carried out with the object of finding the safe loads and speeds for ball bearings, the bearing was allowed to run under a given load from one to five million revolutions of the shaft. The balls were very accurately measured in a Whitworth measuring machine before and after the run with the object of finding the amount of wear. The greatest possible care was taken in the measurements, but in spite of it we sometimes found that on second measurement the balls appeared to be a shade bigger than before the test-undoubtedly due to errors in measurement, although our measurements were carried to the one hundred thousandth of an inch. The only conclusion we could come to was that our method of measuring was nothing like accurate enough. One of the author's colleagues in the Chemical 
Department suggested weighing them on a delicate chemical balance. The author was quite hopeful of success, but in some instances the weights after running appeared to be greater than the weights before running, evidently again due to an error in measurement. This showed that our methods of measurement were still not sufficiently refined. Then came the question of how to discover in a reasonable time whether a ball was overloaded or not. The next method adopted was that of examining the ball under the microscope, which proved quite satisfactory. If a new ball, straight from the makers, be examined under the microscope slight defects will be evident, and after running for a few weeks under a moderate load the surface of the ball improves; if, however, it has been overloaded, the ball appears to be covered with tiny flakes of snow, which are specks where tiny crystals have broken away from the surface of the ball. Such specks cannot be detected with an ordinary lens, but their detection requires a magnification of about 300 or 400 diamcters. As soon as these specks appear it is a sure sign that the ball has been overloaded, and if the test be continued at this load the balls and races will ultimately fail. The way in which the balls themselves fail is interesting. In all the tests that the author has made, involving about fifteen years' continuous work, he has only had about half-a-dozen balls actually break in the testing machine. Nearly all the failures are due to the peeling of the ball, the surface coming away like the peel of an orange. There is one very curious point that the author has not yet fathomed; the balls nearly always peel on one hemisphere only and not on the other. The experiments have given scores of instances in which balls have failed in that way while the remainder of the ball is practically perfect, although by means of the microscope imperfections can be detected. The reason why one half of the ball fails and the other half does not is an interesting problem.

In the races of ball bearings it is important to use simple rings of uniform section. In the early days, many makers made the mistake of drilling holes in the races in order to attach them to the shaft and to hold the outer races in the bearings themselves. The holes were, of course, drilled when in the soft state, and the rings were afterwards hardened and ground, but invariably the races failed in the neighbourhood of the holes. In certain instances races were made with a slight projection or lug for the 
same purpose, but in every case they failed at the lug. The lesults of a great many tests all point to the conclusion that a uniform section of ring should be adhered to, and lateral grooves should be avoided if possible. The author is aware that some makers will not agree with him on this point, but he has tested a great many bearings to destruction, and can nearly always foretell where they will fail, that is where the circular form of ring is departed from.

\section{Fitting the Race on the Shaft.}

In some of the author's early tests two holes were drilled through the inner race or ring of a bearing, through which steel pins were let into the shaft in order to hold the race in position, but as soon as any material load was put on the bearing the pins sheared. The reason for this mysterious action was a puzzle for a time. It was argued that the coefficient of friction, between the balls and races was, say, one thousandth; hence; when the load on the bearing was known, it was quite a simple matter to calculate the shearing stress on the pins, but it was quite insufficient to account for the failure. It occurred to the author that the coefficient of friction to be reckoned with was not the coefficient of friction between the ball and the race, but the static coefficient of friction between the shaft and the ring, since the ring is slightly bigger than the shaft; as the shaft rotates the ring rolls upon it, and that portion of the ring in contact with the shaft is therefore stationary with regard to it. Therefore, the coefficient of friction required for getting the load on the pins is the static coefficient, which is somewhere in the neighbourhood of a third instead of a thousandth, with the result that with a load of $1,000 \mathrm{lb}$. on the bearing there may be $300 \mathrm{lb}$. shearing stress on the pins. Looked at in that light; it entirely accounted for the shearing of the pins. A better method of attaching the sleeve to the shaft therefore had to be adopted. The sleeve was made slightly taper, and forced on to the shaft by a nut on a screwed portion of the shaft. That answered fairly well, except under the heaviest loads. Later on a wellknown maker of ball bearings placed on the market an adapter in which the inside of the bearing is made slightly taper, and a split. adapter which fits it and the shaft is tightened up by means of a nut which draws the adapter ring into the bearing and 
causes it to grip the shaft. It makes quite a good arrangement for moderato louds, but for big loads and high speeds, or where there is much vibration, it is not altogether satisfactory. The best method of attachment is to shrink the inner ring on to the shaft, or to force it on by a screw or hydraulic press, but it is very easy to do mischief in doing so. If too much shrinkage is allowed, the ring expands to such an extent that it jambs the balls in the bearing. It must not be forgotten that a ten-' thousandth of an inch is not a negligible quantity. In a well made bearing there is only an extremely small amount of shake of the balls in the races; hence, if the inner ring be enlarged by: only one or two ten-thousandths of an inch the balls will jamb, and a very much bigger load will be imposed on the balls than is intended; many a bearing has failed from this cause. A safe way of arriving at the amount of the shrinkage is to make it two thousandths of the diameter of the shaft. Another safe rule is that if the inner ring will not slip on when heated in a bath of oil at about $150^{\circ} \mathrm{F}$. too much shrinkage has been allowed. If it slips on very easily there is insufficient shrinkage to hold it firmly; it should just slip on fairly freely when heated up to $150^{\circ} \mathrm{F}$., but it is infinitely better to err on the side of having it slightly too slack than too tight on the shaft.

\section{Entering the Balls in the Bearing.}

In radial bearings having plain, i.e., not grooved, rings, the full number of balls can readily be inserted, but in the case of a grooved race (see Fig. 17, Plate I.), some other method must be adopted for getting in the full number of balls. The usual practice is to pull the inner ring to one side and pack in just over one-half the full number of balls. Then when evenly spaced a spring cage or a solid cage, which is more commonly used at the present day, can be inserted, but only about one-half the full number of balls can be got into the bearing by this means. In order to get in the full number of balls, the races are often grooved at the side, and the extra balls are forced in by a press, or driven in with a piece of copper and a hammer. The method is fairly satisfactory, but, as already pointed out, the rings are liable to crack at the groove. The lateral groove is cut in the races before the bearing is hardened, and it is not quite so deep as the ball race groove. In some of the early bearings the lateral groove was made the same 
depth as the race, and a loose piece was afterwards fitted in, but it was an unsatisfactory arrangement.

In the Skefco bearing (Fig. 18) the full number of balls can be got in quite readily. The outer ring is ground spherically, the centre of the sphere being at the centre of the shaft. There are two grooves in the inner ring of the bearing, which can be tilted to one side to allow the full number of balls to be slipped in. In addition to being able to get in the full number of balls, it has the great advantage that it can be used on a shaft which is

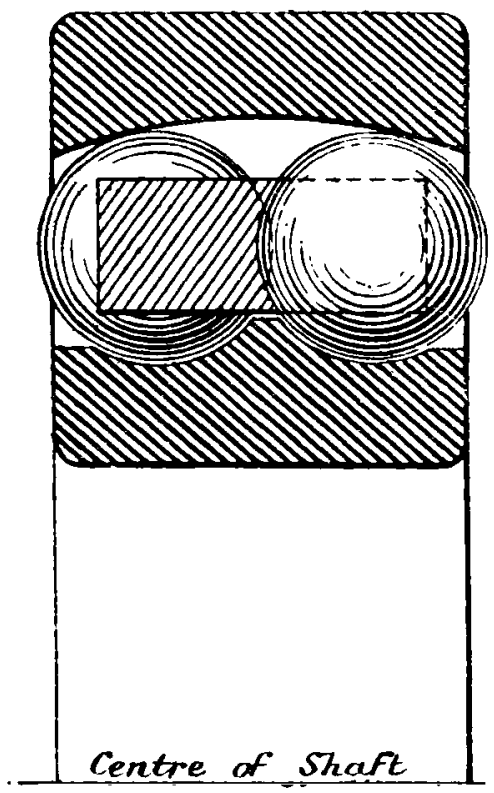

FIG. 18.

very much out of truth. In motor cars and aeroplanes, where the frames spring considerably, this type of bearing lends itself readily to the requirements of the case.

\section{How to Support a big Load on a Thrust Bearing.}

When a thrust bearing is required for big loads, it not infrequently happens that difficulties arise. It is not always possible to get in a sufficient number of balls in a single race to carry the load without making the races of abnormal proportions. 
Some years ago a bearing of the type shown in Fig. 19 was brought out having a large number of balls in a cage which ran on big flat races, but it was altogether a failure, for the simple reason that the collars would spring under the load; thus the inner balls got more than their fair share of the load, and consequently very quickly peeled; the little flakes from these inner balls got in amongst the outer balls, with the result that the whole bearing went to pieces in a very few hours.

Probably the best way out of the difficulty is to use a multiple

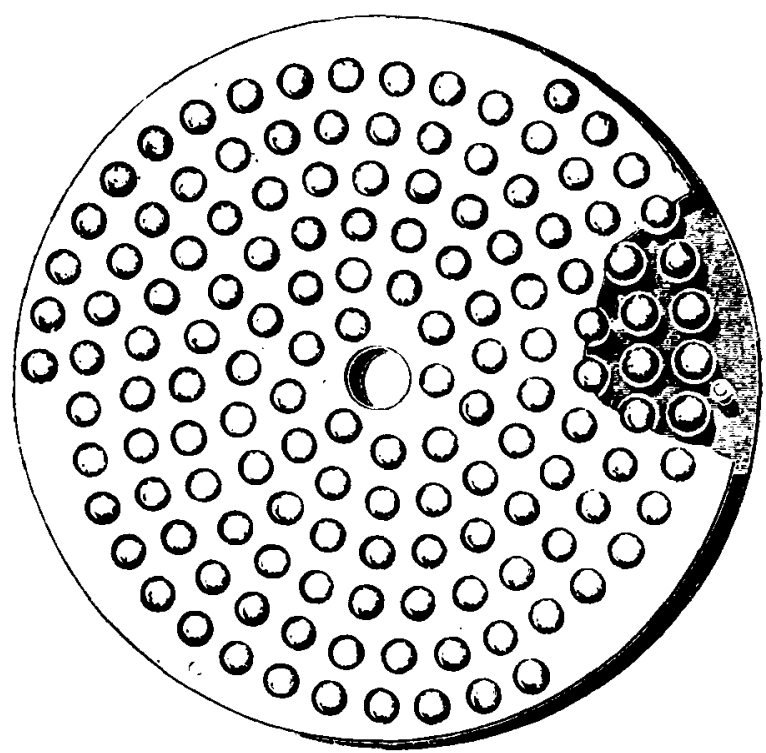

FIg. 19.

ring bearing of the type shown in Fig. 20. Standard types of thrust rings are used, which are mounted on a heavy cast iron housing with linoleum packing below. The lower portion is provided with a spherical seat to allow for the shaft getting out of truth with its housing. In order to exclude dust, a sheet iron ring is provided and dips into a small groove filled with oil. It is just as important to keep a ball bearing free from dust as it is with an ordinary bearing. Users do not always realise that such is the case, consequently many bearings which are GOODMAN. 
otherwise excellent go wrong simply from dust and grit. In Fig. 21, a radial bearing of this type is shown. In this particular oase, standard types of bearings are used which are fixed side by side on the shaft by shrinkage or pressing. The casing itself is lined with linoleum outside the rings. If there is any tendency to unequal loading the linoleum yields to a small extent, and thereby fairly evenly distributes the load over all the rings. If something in the nature of a soft bed is not used, and there is the least spring in the shaft, and there always is spring, then some rings get more highly loaded than others and trouble ensues,

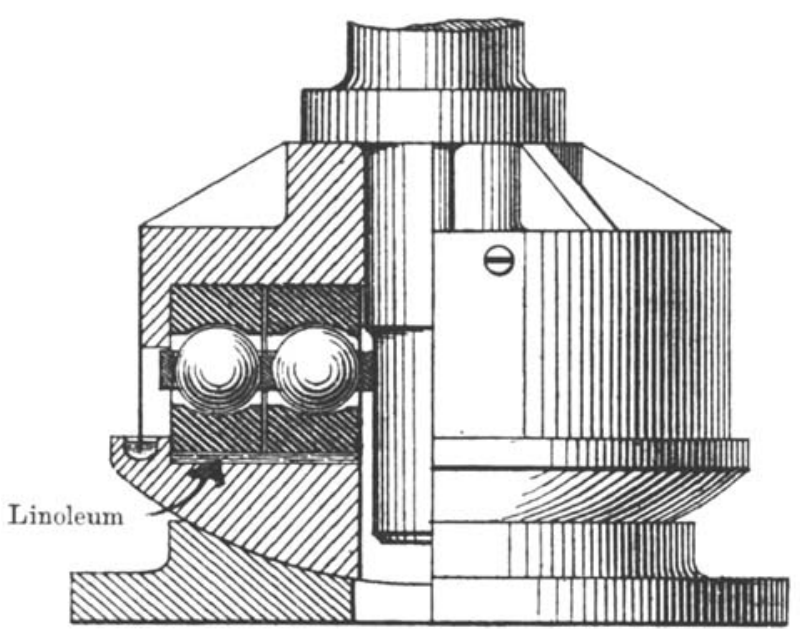

Fig. 20.

but by the use of a linoleum liner all trouble of this kind is avoided. In addition, it is well to make the casing with a spherical seat as shown, so that if the shaft gets out of line it automatically adjusts itself, as in many ordinary swivelled bearings.

\section{Comparative Friction of Ordinary and Ball Bearings.}

A comparison between the friction of an ordinary white metal bearing and that of a ball bearing is shown in Fig. 22. It will be seen that in the case of white metal or gun-metal bearings the starting effort is very much greater than the normal resistance after it has been running for a time. With ball bearings it is just the 
reverse. This is an extremely important point when dealing with machinery that stops and starts very frequently. In all cases the friction in a well made ball bearing is considerably lower than the friction of a shaft running in an ordinary bearing.

\section{Cost of Ball Bearings.}

A ball bearing always costs more than an ordinary bearing capable of earrying the same load, but in some cases the total cost of a machine is actually less when fitted with ball bearings

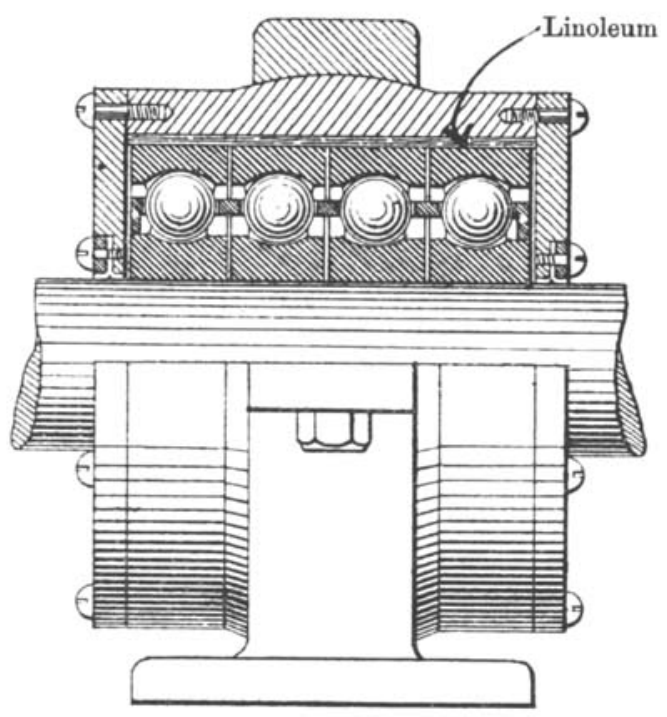

Fig. 21.

than it is with ordinary bearings. Take the case of an electric motor or dynamo. When ball bearings are used they are very short as compared with ordinary bearings, probably only, 'ne-tenth as long. Hence, the shaft can be shortened to a corre-ponding extent, the bending moment is thereby reduced and the lied shortened, with the result that many makers now actually quote a lower price for machines with ball bearings than for machines fitted with ordinary ring bearings. It must not be iorgotten, moreover, that ball bearings require practically no lubri- 
cation, once in two or three months, perhaps, and then simply to prevent rust. If rust could be prevented by any other means, a ball bearing would run just as well without oil as with it. The author is aware that there is a difference of opinion on this point, but he has had sufficient experience with ball bearings to state very definitely that that is the case: but just one word of warning

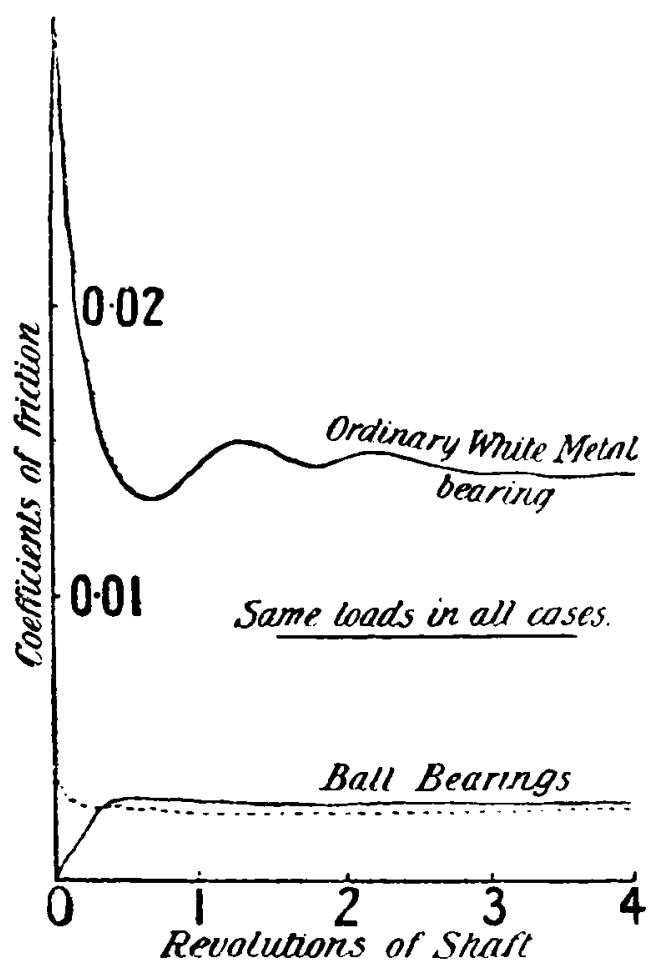

FIG. 22.

-extreme care must be taken about the oil. A bearing may easily be ruined in a few weeks by using improper oil, which sets up corrosion and ruins the bearing very rapidly. There are certain oils and greases on the market which are quite good and others which are not. The author is informed that the best quality of lard oil gives excellent results with ball bearings.

When shafting is fitted with properly made ball bearings, power can be transmitted more efficiently than by any other means 
known. Electrical engineers will probably prick up their ears at this statement, but it is quite easy to prove that power can be much more efficiently transmitted with shafting mounted on ball bearings than it can be done electrically. Of course, under many conditions, the electrical method is a great deal the most convenient way of doing it, but where simple conditions prevail, shafting mounted on ball bearings gives a very high efficiency.

\section{Testing Apparatus.}

In Fig. 23 a machine is shown for testing ball and roller bearings. This particular machine is of interest in that it is the only one in which the load can be applied by a lever and yet allow of the friction moment being measured. In the friction experiments made by Mr. Beauchamp Tower nearly thirty years

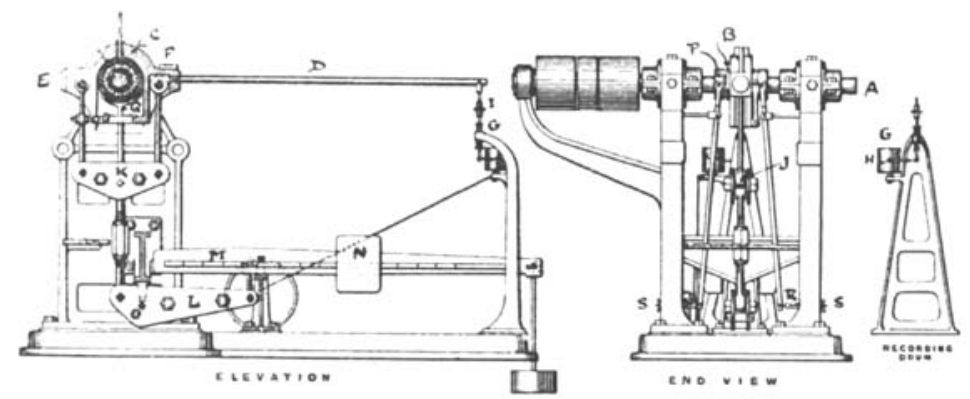

Fia. 23.

ago, he loaded his bearings with dead weights, which made a satisfactory testing machine, but it is a very serious matter to have to constantly lift up and down a 10 or 12 ton load. Such a task requires an army of labourers, and even then the machine becomes very bulky and troublesome; hence many people have aimed at making a friction testing machine in which the load can be applied either by springs or by levers. Many have used springs, but unfortunately such a device involves putting the load on both sides of the bearing at once, which is possible, but highly undesirable with ordinary lubricated bearings, but it cannot be done with a ball bearing, at least, not satisfactorily. In this particular machine the load is applied through the two links JJ. $B$ is the bearing under test; it fits in the stirrup $C$, which is coupled by two links to the cross-head $K$, and the load is applied to the 
central knife edge by means of compound levers; since it is central between the two lower knife edges, and the bearing is central between the two upper knife edges, it will be quite evident that the stirrup and the lever D are free to turn about the centre of the shaft whatever the load may be upon the bearing. The load is applied by compound levers, and the friction on the bearing is measured by an autographical recorder I.G.H, or by a sliding weight on the arm $D$. If the bearing is not perfectly central, the knife edge at $\mathrm{E}$ can be tilted slightly by a screw adjusted lever. It does not matter whether the bearing is dead central or not, because in every case tests are made with the shaft rotating, in the one instance in a clockwise direction, and in the other in a contra-clockwise direction, and the mean of the two tests is taken. In order to measure the end thrust there are two levers; at the lower end of the levers thore are spring balances and
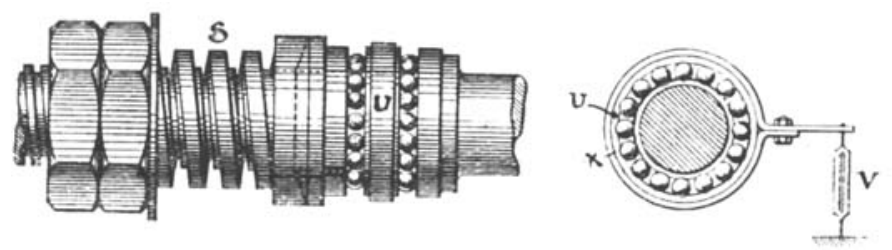

Fig. 24.

thumb screws at $\mathrm{S}, \mathrm{S}$. When the machine is running, the thumb screws $\mathbf{S}, \mathbf{S}$ are tightened up until the bearing is brought to a central position as indicated by a pointer on the bearing. The difference of the readings of the two spring balances multiplied by the leverage gives the amount of end thrust on the bearing. There is a ball bearing interposed between the collar $\mathrm{P}$ and the main bearing $B$. The machine is driven by an electric motor, and a fairly big range of speed can be obtained by means of countershafts and pulleys, and the speed of the motor itself can be varied. Loads of 10 tons can be applied, and the speed varied between about 3,000 revs. per minute and 5 or 6 revs. per minute.

An arrangement for testing thrust bearings is shown in Fig. 24. Two thrust bearings are put back to back, and a strap $\mathrm{U}$ is clamped around them. As the machine rotates it tends to carry the strap and the collars round with it, and the reading on the spring balance $\mathrm{V}$ at one foot radius gives the moment of the friction. 
The load is applied to the bearings by means of a very heavy helical spring, which is compressed to the desired amount by means of nuts; from a previous calibration of the spring in a separate testing machine, the amount of load on the bearing is known from the deflection of the spring. A ball and socket seat is provided at the back in order to ensure that a perfectly even load is imposed upon all the balls.

\section{Safe Working Load on a Ball Bearing.}

The results of the author's experiments have led him to the following formula for calculating the maximum working load on a ball bearing:-

$$
\mathrm{W}=\frac{\mathrm{K} m d^{3}}{\mathrm{ND}+\mathrm{Cd}}
$$

Where $\mathrm{W}=$ the maximum working load in pounds for a ball bearing.

$m=$ the number of balls in the bearing.

$d=$ diameter of the ball in inches.

$\mathrm{N}=$ revs. per minute.

$\mathrm{D}=$ diameter of ball race in inches, the diameter being taken from the point of contact of the ball with the inner race in a radial bearing, and for a thrust bearing the diameter is taken from the centres of the balls.

The constants $\mathrm{C}$ and $\mathrm{K}$ are as follows:For thrust bearings-

C.

Flat races .. 200

Hollow races . 200
$\mathrm{K}$. 500,000 from $1,000,000$ to $1,250,000$

For journal or radial bearings-

C.

$\mathrm{K}$.

Flat races . . 2,000

$1,000,000$

Hollow races . 2,000

from $2,000,000$ to $2,500,000$

The lower values of $\mathrm{K}$ for the hollow races are for bearings of ordinary quality and the higher values for bearings of the best quality.

Some makers' lists give higher loads than those found from the formula, but from actual tests of their bearings the author 
knows that they will not always work satisfactorily under the catalogued loads.

Some of the illustrations given in this paper were published in the author's paper on "Roller and Ball Bearings" in the Proceedings of the Institution of Civil Engineers, Vol. CLXXXIX., and are here reproduced by the courtesy of the Council of the Institution, others have appeared in the author's "Mechanics Applied to Engineering."

Although a great deal of work has been done on the friction of ball and roller bearings, there is yet a great deal more to be done, and the author hopes in the near future that someone will take up this subject, and go into it more thoroughly than he has been able to do. 


\section{THE DISCUSSION.}

Mr. D. J. Smith, in opening the discussion, said: I should like to ask Professor Goodman how it is that the Koppel bearing, Fig. 8, which is used on thousands of small contractors' wagons, only very rarely cuts through the cages. I have had experience of some hundreds of these wagons, which carry about 2 tons per axle, and in very few cases indeed have I ever had any trouble with the roller bearings, though they are frequently of the roughest form of construction. The rollers appear to be merely cut off a bright drawn steel bar, and the cages are very roughly machined, yet they stand up remarkably well. I have also had a good deal of experience of Mossburg bearings', some of which have been in use for eight years and are still standing up splendidly to the work. I had some down a few days ago, and could find hardly any trace of wear, either in the bearing, the shaft, or the cage in which they revolved, and in no case was there any sign of end thrust.

Professor Goodman: What is the load?

Mr. Sмiтh: They are fitted on an automobile. I cannot give the actual load as it is a very variable one, but it is a load which I think would tire out an ordinary ball bearing of equal size fitted in the same place. The author stated that conical roller bearings are quite satisfactory, with which I agree, except for the fact that the makers make them adjustable. He objects to ball bearings being made adjustable, and $I$ think the objection holds good also with roller bearings. The trouble is not that the wear cannot be taken up, but that the adjustment is made by a very fine thread, so that an extremely heavy load can be placed upon them by careless adjustment. I think, therefore, that if no adjustment were provided on conical bearings, as recommended by Professor Goodman for ball bearings, it would be rery much more satisfactory. I do not think I have come across a single case in which a modern conical roller bearing has ever failed on account of faulty material or design, but I have come across many cases in which they have been absolutely ruined by being wrongly adjusted. I have, however, had a lot to do with ball bearings which could be aljusted. The load was applied 
(Mr. D. J. Smith.)

vertically, and the bearings were split horizontally at right angles to the direction in which the load was applied, and these could be repeatedly taken up and adjusted, and I should like to ask the author how, in view of his remarks, he accounts for the fact that it is possible to adjust a bearing of that sort satisfactorily, provided that the load does not come across the point of the adjustment.

Mr. C. R. GARRARD: I think a great many makers are makingthe radius of the race in the neighbourhood of 20 per cent greater than the radius of the ball. I should like to ask whether the author has investigated the destructive effects of pushing the ball over to the side of the race so as to bring a thrust force on to the ordinary annular ball bearing which should not be there. More bearings have been destroyed by that than by anything else.

Mr. H. W. Staner: Will the author explain why the groove is better than a plane surface for the ball to run on? The point is not generally understood.

Mr. L. H. Hounsfield: I should like to ask the author if he will tell us why, in the Hyatt roller bearing, he expected end thrust to correct itself, and why this proved not to be the case? Will he also explain why the Hoffman roller bearing does correct its own end thrust?

Professor H. S. Hele-Srraw: We have had to-night an illustration of the great value of taking up a particular line of research and sticking to it. The author las been at work on this subject for fifteen years, unlike many Professors who are apt to dabble in many subjects, and to skim gaily over the surface of innumerable problems. The best results can only be obtained by concentration, as we see to-night, and I do not think there is one of us here who does not feel that he has learned something. One of the most interesting points was that of the flaking of the balls, and it is not so much an extraordinary thing that this flaking takes place, but that it has never yet been discorered why the ball flakes on one hemisphere and not on the other. This not only shows that we have yet a great deal to learn, but it shows the value of careful observation, as an obscure point, when cleared up, may reveal the secret of the cause of ball bearing deterioration.

The President: I am sure we have all listened with very great pleasure to Professor Goodman's lecture, which I rather wish we 
had heard ten years ago. It would have saved a very great deal of trouble in the early days with ball bearings, which used to fail from all kinds of unaccountable causes. We used to put them in to stand about twice the loads that were specified by the makers, but still failures were prevalent, which we found out by degrees were due to defects in workmanship.

Prof. Goodman, in replying to the discussion, said: The formula I have arrived at for the maximum working load on a ball bearing is the outcome of a very large number of tests. Some years ago, Stribeck, who did some interesting work on ball bearings in Germany, published an expression for the safe load on a ball bearing, but he overlooked the effect of speed. In my earliest experiments, made about seventeen years ago, I found that the speed of the shaft played a most important part, but as the experiments proceeded it was found that, other conditions being kept constant, the speed of the shaft was not the only factor to be reckoned with. After many attempts it was found that the safe working load for ball bearings was dependent upon the speed of rotation of the balls themselves. In order to finally settle this point, a multiple thrust bearing was made consisting of a series of collars threaded on to a shaft, and between each set of collars a cage with a single ring of balls was interposed; each cage contained the same number of balls, but the diameter of the ball path was varied. The load was applied by means of a helical spring; which subjected each set of balls to exactly the same pressure. It was found that for a given load and speed the balls on the biggest ball path failed first, and those on the smallest ball path failed last, thus conclusively proving that the speed of rotation of the balls, and not that of the shaft, was the ruling factor. The formula given in the text is not purely empirical, it has a rational basis, but the constants are obtained from the experiments. In order to bring all the results of many sizes and types of bearings into line, a diagram was plotted with the speed of rotation of the ball as ordinates and loads as abscissae. For purposes of comparison all results were reduced to the equivalent load on one inch balls running on flat surfaces. Balls running in Vee grooves were found to fail at about one-third the load for flat races, and balls running in grooves were found to be safe at from 2 to $2 \frac{1}{2}$ times the safe load for flat races, hence some of the experimental results had to be corrected in these ratios before plotting. When making the above mentioned diagram the result was recorded by 
(Prof. Goodman.)

a - for the cases in which the balls failed, and where the balls remained perfect after from one to ten million revolutions of the shaft the result was recorded by a -. After some hundreds of such records were plotted it was found that a curve could be drawn which separated the failures from the successful runs. The formula already given is constructed to fit this curve. Very few people realise that it represents over fifteen years of patient, tedious work. In some cases each spot represents a month's work, and in no instance less than a week. Several testing machines were kept continuously running during working hours. Those wishing to go more fully into the matter should consult the author's paper in the Proceedings of the Institution of Civil Engineers, already referred to.

In reply to Mr. Smith's question, the reason why no trouble is experienced with the Koppel bearing is undoubtedly due to the very low speed at which they work, and to the low intensity of pressure, only about $\frac{1}{20}$ th of what may be imposed on the best roller bearings. Soine conical roller bearings certainly run satisfactorily at low pressures, but I have not found one that will run well under even a moderate intensity of pressure.

An ordinary single row radial ball bearing cannot, as far as I am aware, be made adjustable. Some time ago I designed an arrangement of ball bearings whereby the "shake" could be taken up. Three radial bearings were fitted side by side on the shaft, the two outer ones supported the shaft, and the inner one was fitted into a cap which, by a special lever and fine threaded screw, could be tightened down in the event of any wear taking place. Of course the adjustment had to be made very skilfully and carefully.

I have not made any tests on the destructive effect of pushing the ball over to the side of the race referred to by Mr. Garrard, but I realise the importance of the matter.

As to the reasons for the grooved race being better than the plain surface, I would refer Mr. Staner to Hertz's theory, also to Heerwagen's work on this subject, both of which will be found in Engineering in 1901 and 1902.

Mr. Hounsfield's question with regard to the end thrust being very great with some types of bearings and very small with others is a most interesting topic, but it would take too long to go into it on this occasion. 


\section{THE DESIGN OF BALL AND ROLLER bEARINGS. Plate I}

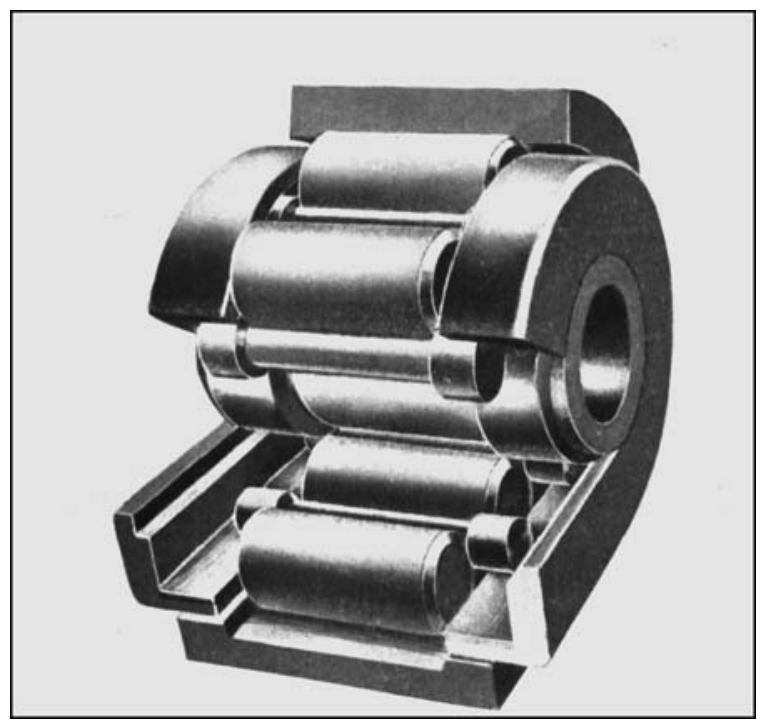

Frg. 11.

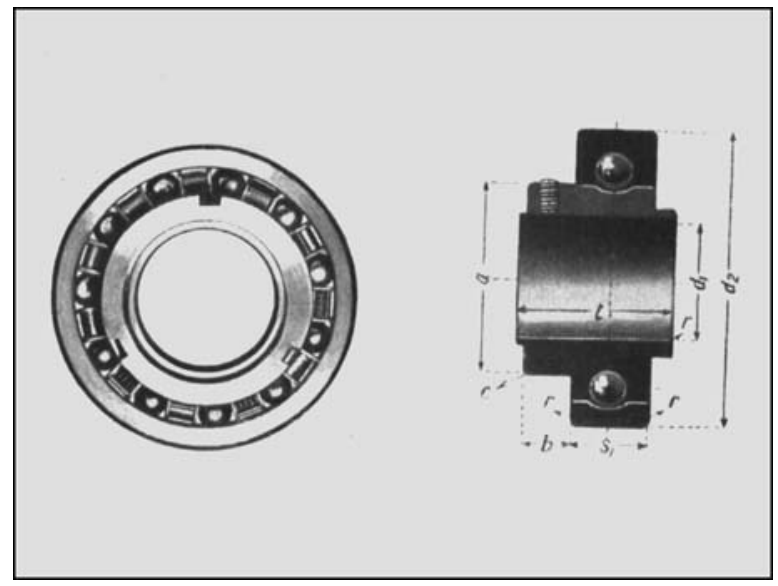

Fia. 17. 